\title{
Research on the Network Violence and Moral Education Countermeasures of Adolescents in BaoShan City \\ Wenyu Li
}

Curriculum and Instruction, Baoshan University, 678000, China

*Corresponding author. Email: 564462017@qq.com

\begin{abstract}
With the innovation of network technology and the gradual popularization of mobile terminals, the number of Internet users in China is increasing year by year, among which the main group is teenagers. By virtue of advantages, the Internet has derived the form of network virtual society, which has a wide impact on teenagers' way of thinking, way of life, ideological and moral concepts, resulting in the confusion and loss of moral awareness and moral behavior of teenagers' ideological problems. There is urgent need to strengthen the governance of cyberspace. Combining with the relevant knowledge, moral education based on the perspective of all-round education, with Baoshan city as the research site, should put forward from the municipal government, network media, schools, the four aspects of their own youth to make corresponding measures, to prevent teenagers network violence risk, reduce the network violence to the harm of teenagers, for Baoshan city youth to create a clear network space.
\end{abstract}

\section{Keywords: Adolescents, Network Violence, Moral Education.}

\section{INTRODUCTION}

In April 2016, President Xi Jinping pointed out in his speech at the symposium on cyber security and informatization that "the Internet is the destination of the common heart of hundreds of millions of people. No one will ever live like this in a space full of falsehood, fraud, attack, abuse, terror, pornography, violence. ${ }^{1}$ To investigate criminal responsibility to strengthen the governance of cyberspace governance objectives, strengthen the focus of network content construction, do strong paste bar vertical publicity, foster positive and healthy, upward to the good network culture, for the vast network spray is extremely young people physical and mental health to create a clean and upright network security.

In recent years, mobile phones, computers and other electronic devices have become a small part of young people's life, which leads to great changes in young people 's life and learning. Adolescents have long-term exposure to the network, and the risk of involvement in cyber violence is increasing, which will affect the health

1 Speech by General Secretary Xi Jinping at the Symposium on Network Security and Informatization [EB/OL]. Cyberspace Administration of China, http://www.cac.gov.cn. of adolescents to establish a correct concept of self-awareness and network security. In daily network communication, online campus violence occurs frequently, and the main forms of online violence show a trend of younger market. From the perspective of the harmfulness of network violence, compared with traditional violence, network violence spreads faster, causing great harm and wider influence. From the young trend of network violence subjects, more and more middle school students are exposed to network violence, and some students become perpetrators or victims.

In summary, young people in the use of the network problems emerge in an endless stream, they become the victims of cyber violence, but also become the perpetrators of cyber violence. Schools, as the main position for cultivating adolescents, have far-reaching significance in exploring the harm of cyber violence to adolescents and seeking solutions to cyber violence.

\section{STATUS OF RESEARCH}

The current research on the connotation of network violence, different fields, different angles, different scholars have different understanding of the connotation of network violence. First from a sociological point of 
view. The spread of cyber violence is mainly to launch personal attacks on victims on various clients, which may develop into a communication activity in real life (Jiang, 2011). Network violence is intense, emotional, mostly anonymous, venting network phenomenon. Personality difference plays an important role in Internet language violence. Internet violence is the behavior influenced by potential emotion, need intensity and drive level (Zhou, 2013).

Many researchers generally agree that the failure of legal supervision has caused the occurrence of cyber violence. The reasons are one-sidedness of citizen journalism, anonymity of network environment and herd mentality of net name (Fan, 2012). The space-time characteristics of cyber violence crimes, social control omissions, potential cyber violence perpetrators and victims constitute subjective and objective elements are the causes of cyber violence. Internet users often lack rational judgment on things and are affected by emotions to make ' follow the trend ' behavior. The lack of rationality of network communicators and the lack of network gatekeeper function are the main causes of network violence. (Hou, 2014)

In terms of strategies to deal with cyber violence, domestic scholars have mainly conducted research from the following aspects. The first is government supervision and accelerated legislation. Secondly, network operators should strengthen their own management. Network operators should actively implement the network real-name system (Shi, 2016). Then, the free expression of netizens on the Internet can not violate laws and regulations, can not infringe on the legitimate rights and interests of others, we must have this legal consciousness. Finally, we should actively carry out socialist core values education, legal education, etc., and use major network platforms to vigorously guide netizens to express rationally and speak carefully in cyberspace $(\mathrm{Li}, 2017)$

\section{QUESTIONNAIRE DESIGN AND SAMPLE SELECTION}

\subsection{Questionnaire Design}

On the basis of extensive literature collection, with the help of the National Authority Network Violence Impact Scale, the questionnaire on the impact of network violence on college students and the questionnaire on the impact of network violence on middle school students are completed.

Through this survey, a total of 590 valid questionnaires were collected, and SPSS 26.0 software was used to test the reliability and validity of relevant research data. First, we used Cronbach's alpha reliability coefficient to estimate the internal consistency of the questionnaire. The results showed that the overall reliability coefficient of the 29 questions of the whole questionnaire was 0.943 ; secondly, the exploratory factor orthogonal variance maximization method is used for principal component analysis to test the structural validity of the questionnaire. The results show that the KMO coefficient of the whole questionnaire is 0.952 , and the Bartlett's test is significant ( $\mathrm{p}<0.001)$, which proves that the reliability and validity of the data are very ideal.

There are 29 questions in the questionnaire, which are mainly divided into five parts. The first is the basic information, including gender, education background, professional type, and the difference of origin. Second, the basic situation of college students' network activities; third, college students' network violence related experience; fourth, college students' cognition and attitude to network violence; fifth, the possible influencing factors of college students' network violence and their corresponding views and suggestions on network violence. There are eight questions in the interview outline, involving four aspects, including college students' understanding of network violence, their own or nearby students' relevant experience, the influencing factors of network violence and the vision of network space construction.

\subsection{Sample Selection}

One university (Baoshan College), two high schools (Baoshan No.1 Middle School and Longyang No.1 Middle School) and two junior high schools (Baoshan No.1 Middle School and Longyang No.1 Middle School) were selected as the survey sites in Baoshan City. Through on-site questionnaire survey, the survey samples were selected according to the proportion of the basic number of junior high schools, senior high schools and universities in the pilot study. According to the number of primary and secondary schools in Yunnan Province in Baoshan City in 2018, the number of middle schools in Baoshan City (the city) was about 1,194 million, including about 403,000 high school students and about 791,000 junior high school students. The number of full-time college students in Baoshan University is about 8774 ( 0.88 million ), excluding junior high school students : high school students : college students $=3: 2: 1$, randomly selected 300 junior high school students, 200 high school students and 100 college students to participate in the questionnaire.

According to the previous research results, to develop a network violence impact research interview outline, randomly selected 30 junior high school students, 20 high school students and 10 college students to participate in the interview. 


\section{RESEARCH RESULTS ANALYSIS}

\subsection{Status of Cyber-Violence}

From the analysis of the questionnaire, it can be found that most middle school students spend about 2 hours or $2-4$ hours a day online. $62 \%$ of college students spend more than 6 hours a day online, or even more than 12 hours a day, which is easy to cause excessive online. Students have two extreme online speech attitudes. One is in the state of enthusiastic participation in the network, and the other is in the state of watching others' speech. Whether middle school students or college students, they are basically 'encountering topics they know or are interested in', 'encountering things they feel like' or 'some situation makes them very angry or confused', which indicates that students are relatively active in online communication, and occasionally express views on situations they are interested in or understand, which basically remains in the normal range of online communication. However, college students ' network participation will be improved to a certain extent when some behaviors of ' empathy ' and ' anger ' appear.

\subsection{Impact of Network Activities}

College students in the network activities will be affected by various factors, through the design of some problems in the questionnaire to analyze the current family, school, law and other factors on the influence of students ' network activities, as well as these factors and prevent and deal with the relationship between college students ' network violence. Questions about ' who has a greater impact on your online opinion ' show that younger children are more likely to be affected by other people's channels, so the impact of official numbers, star numbers and peers around them is particularly significant. With the growth of age, college students have their own ideas when they look at network events, and they will first think independently when they express their opinions. However, due to the complexity of interpersonal communication around college students compared with junior high school students, they have more access to network news channels, and are more likely to blindly follow the crowd.

\subsection{Understanding of Network-Related Laws and Regulations}

Although China's laws and regulations against cyber violence is not perfect, but the current state has introduced a network security and network ecological governance related laws and regulations. Understanding these laws and regulations is also an important part of regulating and constraining people's online activities. Through the investigation, it is found that students know little about the laws and regulations related to network security. The opinions and behaviors of students' authors in the network are seriously affected by many factors. The constraints and supervision of laws and regulations, the reply of official authority, the different views of peer groups, and the family and university are all important factors affecting students' personal thoughts and behaviors of network culture. It is urgent to strengthen the publicity of network law.

\subsection{The Participation of Network Violence}

Based on the possible situation of network violence, that is, the use and purpose of students' network violence speech, and the survey data of forwarding unconfirmed hot news, $40 \%-60 \%$ of students will occasionally use some fierce and extreme languages in the network. In adolescence, students have strong aggressive psychology, which leads to the occurrence of cyber language violence. There are also college students using aggressive language because of bad mood want to vent emotions. In the interview, there are also college students to supplement the use of cyber violence generally in ' when the things done by both sides are very contrary to the principle ', ' with their way to cure their body ', ' when you see campus violence, domestic violence, lack of education and other hateful good things happen frequently'. It can be seen that many students answer is to maintain the heart of 'justice'; some students are out of emotion, in order to vent their emotions and dissatisfaction; some students are ' to seek stimulation or sense of existence ' and ' driven by certain interests '. Students with relatively young age are supplemented to "maintain their idols".

\subsection{Participation in Cyber-Language Violence}

In students ' daily life, the discussion of movie stars, sports stars, singers and other topics is the normal life, and many college students often pursue stars on the Internet. Coupled with social media attention to stars and marketing too much, often a star ' $\mathrm{s}$ ' hot search ' will also drive college students' network emotions and behavior. In the student stage, excessive maintenance of the star causes online's scolding', resulting in the use of aggressive language and other network violence, but also by others.

\subsection{Violence Participation in Network Behavior}

There are many ways for college students to participate in network language violence, such as remote attack of network words, human flesh search, and forwarding hot news confirmed by any media. However, most of the middle school students have not finally shown what the purpose of direct violence against others on the Internet is. When these students are confused by bad information in the network, they are invisible to 
participate in network violence, such as forwarding some hot articles that are inconsistent with the facts. Students lack further understanding of the nature and ability of network violence, confusing the form of network violence, network freedom and network supervision. Most Chinese college students may not go to ' human flesh search ', but sometimes forwarding unapproved high-calorie news will virtually spread false main information, including indirect cyber violence.

\section{COUNTERMEASURES AND SUGGESTIONS}

\subsection{Baoshan Municipal Government Carries Out Prevention and Guidance at the Macro Level}

\subsubsection{Baoshan Municipal Government to}

Improve and Refine the Network of Ethical Laws and Regulations, Intervention in Cyber Violence

Detailed special relevant laws, high precision devastating combat cyber language violence. Reliance on law to restrict the nature of cyber-violence is a common traditional practice in the world. Baoshan Municipal Government should actively respond to national policies and implement the network real-name system from the background of network supervision. Users must be required to provide real identity information, otherwise they cannot access the Internet. Once network violence occurs, relevant departments can quickly collect data from the background, identify the real identity of the account subject, and clarify the subject of responsibility in a timely manner, so as to quickly and effectively implement accountability.

\subsubsection{Baoshan Should Actively Build Interest Expression and Coordination Mechanisms to Promote the Orderly Release of Pressure}

The new generation of social networks after 90s and 00s actively participate in hot public opinion, and have their own understanding and voice of social hot events. Baoshan also needs to reasonably construct a new channel to express their own interests. From both objective and subjective aspects, efforts should be made to avoid incidents of cyber violence among young people, and to avoid narrow channels of political intervention that do not allow young people to express their views on the Internet. Although various institutions in Baoshan have some government social platforms, some have become "zombie accounts". They rarely respond to Internet users' queries and even shut down other functions of comment, cutting off the establishment of communication channels. Therefore, Baoshan governments and enterprises need to pay attention to the systematic construction and development of their government affairs micro-blogs and public numbers, and the government affairs public opinions involving particularly important and major emergencies should be quickly responded and timely issued.

\subsection{Social Media Should Guide Public Opinion as 'Gatekeepers'}

\subsubsection{Develop Big Data and Artificial Intelligence Technology to Timely Detect and Guide Network Public Opinion.}

Baoshan municipal government should introduce big data and artificial intelligence technology, and rationally use the massive data left by teenagers in cyberspace to analyze teenagers ' network behavior is an important means to deal with Internet risk. Children are inseparable from electronic products. Mobile phones, computers and other communication terminals are tools for adolescents to connect with the network society. When adolescents use these tools, they will generate useful data, including use traces, use preferences and so on. Once youth cyber violence occurs, explicit information can be obtained through the analysis of these data, and protective measures should be taken to prevent the leakage of youth privacy information and the emergence of new cyber violence.

\subsubsection{Government Network Operators Should Upgrade the Access Threshold for Self-Media Operation and the Platform Should Abide by Professional Ethics}

Compared with the traditional media-related platforms, the emerging We-media platform releases and fans with a large number of Tik-Tok accounts, flash accounts, micro-blog accounts, WeChat public accounts, column creators and other fixed groups of readers, the focus of interpretation of hot events can effectively spread, have a great guiding role for young people. Baoshan City has created a lot of We-Media platform accounts in recent years. Online publishing shop visits, evaluation and other video, public articles on multiple Internet social platforms. Some of the We-Media platform accounts with certain research work in the professional field and special professional characteristics play a crucial role in stabilizing public opinion in social hot events. 


\subsection{School level innovation ideological and political, moral education method}

\subsubsection{Improve the Management Mechanism to Deal with Network Violence, Improve the Campus Network Security}

Universities should improve the management system of students ' online behavior. Because part of college students ' online behavior depends on student accounts, college students often use computers and networks on campus. Our school should formulate a practical and feasible campus network management system according to its own actual situation, increase the supervision and control of students ' network use, and improve the construction focus of campus network, so as to use big data and artificial intelligence platform to detect the overall situation of students ' network use, and guide students to collect more resources from the Internet to learn text materials in a healthy, safe and scientific way. And strengthen the network self-discipline consciousness, strengthen moral education, protect children from network violence. Strengthen all kinds of bad information and website spam, establish network illegal content interception filtering system, purify the information source of each input port, crack down on pornographic images and violent culture, build green campus life.

\subsubsection{Update the Content and Methods of Ideological and Political Education to Improve the Network Literacy of Adolescents}

The cultivation of network literacy personality should include the relevant concepts of rule of law and network ethics into the setting of ideological and political theory courses and basic education moral education courses. Let students and children learn to use advanced Internet platform reasonably, guide students to cultivate the concept of rule of law and self-discipline of network behavior. Schools should pay attention to the good education of network ideological and political education, innovate the theme content of ideological and political education, and create a cultural environment for ideological and political education.

\section{CONCLUSIONS}

With the development of mobile terminal technology, the threshold of Internet access is reduced, and the means of network violence not only challenge the law and ethics, destroy the healthy network external environment, but also destroys the healthy external environment of the network, and also affects teenagers' ideological value cognition and behavior cultivation. From the perspective of moral education, we should look at the network violence, the harm to young people and the reasons why the most violent network of young people emerge in endlessly. From the perspective of all-round moral education, we should put forward countermeasures and emergency measures. From the government, media, schools and young people themselves, we should call on the contemporary society to pay attention to the violence of young people's network society, strictly prevent and guide from different aspects, and jointly create a clear network society.

\section{REFERENCES}

[1] Xi Jinping on Governance (Volume I) [M].Beijing: People's Publishing House, 2018.

[2] Xi Jinping on Governance (Volume II) [M].Beijing: Foreign Language Press, 2017.

[3] General Secretary Xi Jinping's speech at the symposium on network security and informationization [EB/OL]. TheNational Internet Information Office, http://www.cac.gov.cn.

[4] Liu Wen, Li Ke's research framework on cyber language violence based on critical discourse analysis [J]. Journal of Northeast Normal University, 2017 (1).

[5] Publicity Department of the Central Committee of the Communist Party of China General Secretary $\mathrm{Xi}$ Jinping series of important speech books [M].Beijing: Learning Press. People's Publishing House, 2016.

[6] Fan Cuiying. Network moral psychology research [M]. Beijing: World Book Publishing Company, 2012

[7] Jiang Fangbing's network violence, concept, root causes and countermeasures are based on the perspective of risk society [J].Zhejiang Academic Journal, 2011 (6).

[8] Hou Denghua, Privacy Protection in We Media Era - from the Perspective of Human flesh Search [J]. Jurisprudence, 2014 (9).

[9] Liu Wen, Li Ke's research framework on cyber language violence based on critical discourse analysis [J]. Journal of Northeast Normal University, 2017 (1).

[10] Shi Wei, Sun Lili. On Strengthening the Construction of Spiritual Civilization in China's Network Virtual Society [J]. Theoretical Journal, 2013 (12).

[11] Zhou Xingsheng. Youth network ethics [M]. Beijing: Guangming Daily Press, 2013. 